\title{
Price, public policy, and smoking in young people
}

\author{
Eugene M Lewit, Andrew Hyland, Nancy Kerrebrock, K Michael Cummings
}

\begin{abstract}
Objective-To examine the effect of cigarette taxes, limits on public smoking, laws regulating access to tobacco by young people, and exposure to pro-tobacco and anti-tobacco messages on smoking participation and the intention to smoke among ninth-grade students (aged 13-16). Data sources-Two cross-sectional, school-based surveys (total of 15432 responses) of ninth-grade students conducted in 21 North American communities in 1990 and 1992 in conjunction with the Community Intervention Trial for Smoking Cessation.

Outcome measures-A ninth-grader was classified as a smoker if he or she reported smoking a whole cigarette on at least one of the 30 days preceding the survey. Among non-smokers, a positive intention to smoke was attributed to those who claimed they probably or definitely would be smoking within a year.
\end{abstract}

Results-Both smoking participation and the intent to smoke were related to differences in cigarette prices, with estimated price elasticities of -0.87 and -0.95 , respectively. Boys were far more sensitive to price than girls with respect to smoking participation (elasticities of -1.51 and -0.32 , respectively); however, the effect of price on the intent to smoke was similar for boys and girls. Policies limiting minors' access to tobacco (a minimum purchase age of 18 years, a ban on cigarette vending machines, and a ban on giving away free samples of tobacco products) were associated with reductions in participation and intention to smoke. Exposure to tobacco education in school was associated with decreased participation and intention to smoke. Policies that prohibited smoking in public places and in schools were not significantly related to the smoking patterns of ninth-graders. Frequency of exposure to pro-tobacco advertisements was marginally associated with increased participation and intention to smoke; paradoxically, frequency of exposure to anti-tobacco advertisements was correlated with an increased likelihood of smoking.

Conclusions-Policies limiting access to tobacco by young people, increasing education about the effects of tobacco use, and a sharp and sustained increase in real cigarette excise taxes are likely to be most successful in accomplishing the US Food and Drug Administration's goal of cutting the smoking prevalence of adolescents in half over the next seven years.

(Tobacco Control 1997;6 (suppl 2):S17-S24)

Keywords: adolescents; tobacco access policies; tobacco tax

\section{Introduction}

Considerable progress has been made in reducing cigarette smoking. A variety of policies including dissemination of information on the deleterious health effects of cigarettes, anti-smoking media campaigns, limits on tobacco advertising, restrictions on smoking in public and private places and increased cigarette excise taxes have all contributed to the decline in tobacco use. ${ }^{1}$ However, continued reduction in the prevalence of smoking among young people has stalled. Recently released data show that cigarette smoking among students in grades 9-12 (aged $14-18$ ) increased from $27.5 \%$ in 1991 to $30.5 \%$ in 1993 to $34.8 \%$ in 1995 . $^{2}$ This trend, and a growing focus on the addictive nature of cigarette smoking, has led to increased emphasis on developing and implementing policies to discourage cigarette smoking among young people. The polices include establishing and enforcing a minimum legal purchase age for tobacco products, restricting vending machine sales of cigarettes, and limiting the distribution of free sample cigarettes. The policies were first implemented at the state and local level. However, the recently enacted Synar Amendment requires states to demonstrate that they are enforcing prohibitions on the sale and distribution of tobacco products to those under 18 years of age. In addition, the US Food and Drug Administration (FDA) has proposed a number of regulations to further regulate the tobacco industry to curb teen smoking. These proposed regulations, which would strengthen federal restrictions on sales to minors, would also limit tobacco industry promotional and advertising activities thought to be targeted toward young people and would require each tobacco company with significant sales to children to educate them about the dangers associated with using tobacco products. ${ }^{3}$

This paper examines the effectiveness of several tobacco control policies in curbing cigarette smoking among young people, with particular focus on smoking participation and the expressed intention to smoke among ninth-grade students (aged 13-16). First we review recent research that has focused on the effect of cigarette prices (taxes) and other policies on smoking in young people. We present the datasets and methods used in our analysis and then our estimates of the effects of various public policy instruments on smoking 
behaviour for all ninth-graders in our sample and among boys and girls separately. We conclude with a discussion of the implications of our findings for public policy designed to reduce smoking among young people.

PREVIOUS RESEARCH

Although numerous econometric studies of the demand for cigarettes have been published, relatively few have focused on the young. Many of these studies were reviewed in 1994, in an Institute of Medicine report, Growing up tobacco free, ${ }^{4}$ and in Preventing tobacco use among young people: a report of the Surgeon General. ${ }^{5}$ All but one of these studies show a significant effect of price on smoking behaviours in young people. Estimated price elasticities for the young are substantially higher in absolute value than estimated price elasticities for adults. ${ }^{6}$ Lewit $e t a l$ and Grossman $e t a l^{\beta}$ find the estimated price elasticity of demand for cigarettes is -1.44 and -0.76 . Wasserman et al did not find a significant association between cigarette price and demand in young people; this finding is attributed to the inclusion of measures of local restrictions on smoking in public places and worksites in their models. ${ }^{9}$ Subsequent studies, principally by Chaloupka and a number of different co-investigators, confirm the conclusions of Lewit et al and Grossman et al and do not find the estimated price elasticity of demand is sensitive to the inclusion in the models of clean indoor air laws. ${ }^{10-13}$

In a recent study, Chaloupka and Grossman use data from the 1992, 1993, and 1994 surveys of eighth, tenth and twelfth-grade students (aged 13-14, 15-16, and 17-18, respectively) conducted by the Institute for Social Research at the University of Michigan, to examine the effects of cigarette prices and other tobacco control policies on smoking in young people. ${ }^{13}$ Their estimate of the overall price elasticity of demand, -1.31 is consistent with those reported by Lewit et al and Grossman et al, and indicates that large increases in cigarette prices, perhaps induced by increases in cigarette excise taxes, would lead to sharp reductions in smoking in young people. Consistent with the results of Wasserman $e t a l$, they also found that stronger restrictions on smoking in public places could lead to significant reductions in the prevalence of smoking among the young, and also that limits on smoking in schools would reduce average cigarette consumption among young smokers. ${ }^{9}$ Although they do not find evidence that limits on the availability of tobacco products reduce smoking in young people, they attribute this lack of effect to the relatively weak enforcement of these laws.

Aside from the recent Chaloupka and Grossman study, the effects of policies designed to limit access to tobacco by the young have not been examined in large, nationally representative data sets. However, several smaller scale studies suggest that these interventions can be effective if enforced. For example, Di Franza et al report that minimumage purchase laws have had little success in reducing tobacco use in young people as they are frequently poorly enforced." Jason et al, however, report that smoking in young people fell significantly in Woodridge, Illinois following aggressive enforcement of a law restricting sales to minors. ${ }^{15}$ Weinbaum et al found the percentage of retailers willing to sell tobacco to minors in California was significantly reduced after the passage of a statewide law requiring statewide enforcement of the minimum purchase age law. ${ }^{10}$ Similarly, Altman et al report that community-wide education efforts in Santa Clara County, California led to a reduction in smoking in the young. ${ }^{17}$

Tobacco companies spend billions of dollars annually on advertising and promoting cigarettes, making cigarettes the second most promoted consumer product (after automobiles) in the United States. Accordingly, attention has increasingly focused on the effects of these advertising and promotional activities on smoking in young people. Despite a growing body of scientific literature that examines the relationship between these promotional and advertising activities and young peoples' awareness of and attitudes about smoking and tobacco marketing practices, there are no published studies of the direct effect of cigarette advertising on smoking in young people. Lewit et al, however, did examine the effect of the US Federal Trade Commission's fairness doctrine on smoking in the young. ${ }^{7}$ The doctrine required that anti-smoking messages be broadcast widely between 1 July 1967 and 31 December 1970. During that period, pro-smoking advertising was still allowed on the broadcast media. Following the ban on pro-smoking advertising on the broadcast media which began in 1971, the level of broadcasted anti-smoking messages declined substantially. Lewit et al found that having both sets of messages on radio and television led to a reduction in teenage smoking rates; the effect was strongest during the first year of the anti-smoking messages. ${ }^{7}$ The study also reported some evidence that the ban on broadcast advertising had a modest effect in curtailing teenage smoking. Taken together, these finding suggest that policies aimed at restricting pro-smoking advertising and increasing anti-smoking messages can have at least a moderate impact.

In summary, although it appears that increased cigarette prices should reduce smoking in young people, the size of the effect is unclear. The same conclusion can be drawn about the impact of clean indoor air laws on smoking in the young and there is even less evidence about the effects on smoking behaviour of restrictions on access by young people, including minimum-age purchase laws, and bans on vending machine sales, and restrictions on tobacco advertising and promotional activities. This paper uses data from a school-based survey of ninth-grade students in 21 North American communities from the Community Intervention Trial for Smoking Cessation (COMMIT) to examine the effect of several tobacco control policies on two 
measures of adolescent smoking behaviour: smoking participation and non-smoker's intention to smoke. The policies considered in the analysis include cigarette price, the COMMIT intervention, clean indoor air restrictions, school smoking education and policy, minimum legal purchase age restrictions, bans on vending machines and free samples, and pro-tobacco and anti-tobacco media exposure. By measuring the direction and magnitude of the effect of these policy variables on adolescent smoking behaviours, this research explores the effectiveness of these policies in curbing cigarette smoking among young people.

\section{Methods}

DATA

The data used in this analysis are from two cross-sectional, school-based surveys of ninthgrade students in 21 communities. These surveys were conducted in the autumn of 1990 and 1992 in conjunction with COMMIT. The sample included all 11 COMMIT intervention communities and 10 of the paired comparison communities. Two communities were in Ontario, Canada; the balance were American cities. The design and primary outcomes of COMMIT have been described elsewhere. ${ }^{18-21}$

The sampling frame included ninth-grade classrooms, from which a large enough random sample of classrooms was selected to yield approximately 400 ninth-grade students per community. All students in attendance on the day of survey administration for a selected classroom were surveyed. Both public and private schools with more than 50 ninth-grade students were included in the sampling frame.

In both years, two to three weeks before survey administration, a consent letter was sent to each student's home. The consent letter instructed parents to contact the school if they did not wish to have their child participate in the survey. In addition, before administration of the survey in each classroom, students were given the option not to participate. Students who chose not to complete the survey were asked to sit at their desks and read or work quietly. In 1990, an average of $99 \%(412 / 416)$ of eligible classrooms participated (range 84$100 \%$ ) in the survey yielding an average of 405 ninth-graders per community. In 1992, an average of $98 \%(441 / 452)$ of eligible classrooms participated (range 76-100\%) in the survey yielding an average of 422 ninth-graders per community. Student and parental refusal rates were $4 \%$ in both survey years. For this analysis, data from the $\mathbf{8 5 0 4}$ ninth-graders in 1990 was pooled with the 8858 ninth-graders in 1992 to yield a total sample size of 17362 respondents.

After eliminating respondents with missing or inconsistent data, a sample of 15432 subjects was obtained. Table 1 contains descriptions, definitions, and descriptive statistics for the variables employed in the analysis, some of which are described in more detail below.

All respondents were asked about their current, past, and expected future smoking behaviour. Many different measures of smoking by young people were obtained in the COMMIT surveys. This study focuses on two characteristics of their smoking behaviour: smoking participation and non-smoker's intention to smoke. Smoking participants were defined as those who reported smoking at least one whole cigarette on one or more of the 30 days preceding the survey. Intention to smoke among non-smokers was measured by positive responses to the question: "Do you think you will be smoking cigarettes one year from now?". Analyses were performed for some of the other measures of smoking behaviour in the dataset. In general, the results were consistent with those reported in this paper. We chose to report our results for smoking participation because that measure is of greatest policy relevance and has been studied in all previous comprehensive studies of the effects of policy on teenage smoking behaviour. Because of the age of the subjects in our sample, intent to smoke among non-smokers has particular policy significance. We do not report results for quantity smoked by smokers because our sample is very young and many respondents were likely only experimenting with smoking for the first time. As a result, quantity smoked is highly variable and is likely measured with considerable error.

Based on the survey data, a variety of independent variables were constructed to control for non-policy related factors affecting cigarette demand. These variables including age, race, and gender of the adolescent, as well as the survey year are described more fully in table 1 . To control for any effects of the COMMIT trial on ninth-graders, an indicator variable denoting communities under the COMMIT intervention condition was created. In addition, the surveys provided information on a policy-related variable, tobacco education in the schools. This variable (cumulative number of tobacco classes) is measured by the number of grades (first through eighth) in which the adolescent reported that tobacco use and its effects were discussed during a regular class period.

Based on each respondent's state or province of residence, cigarette price and tobacco control policy variables were added to the survey data. Nominal 1990 and 1992 cigarette prices for each community were taken from The tax burden on tobacco. ${ }^{22}{ }^{23}$ Prices reflect the average retail price of a pack of 20 cigarettes, inclusive of general sales or gross receipt taxes. Nominal 1992 cigarette prices were deflated to 1990 dollars using the American consumer price indices for 1990 and $1992 .^{24}$ Nominal Canadian tax-inclusive prices are courtesy of the Non-Smokers' Rights Association (Canada) ${ }^{25}$ and were deflated to 1990 dollars using the Canadian consumer price indices for the years 1990 and $1992^{26}$ and converted to American dollars using the appropriate exchange rate. ${ }^{27}$

To control for cross-sectional variation in the cost of living as experienced by ninth-graders, cigarette prices were adjusted by an index constructed specifically to reflect cross-sectional 
Table 1 Variable definitions and descriptive statistics

\begin{tabular}{|c|c|}
\hline Variable & Definition, mean $(\mu)$, and standard deviation $(\pi)$ \\
\hline
\end{tabular}

Smoking participation

Non-smokers intention to smoke

Dichotomous indicator $=1$ if the youth reports smoking in the past 30 days; otherwise $=0 . \mu=0.21, \sigma=0.40$

Dichotomous indicator $=1$ if a youth who has not smoked in the past 30 days thinks he/she will be smoking within one year;

otherwise $=0 . \mu=0.19, \sigma=0.39$.

Cigarette price

Average real adjusted cigarette pack price in 1990 US dollars. Real price is adjusted by community specific cost of living index. $\mu=1.95, \sigma=0.46$

Clean indoor air restrictions

Index of local clean indoor air restrictions within a given community constructed as the sum three separate indices. The worksite index consists of a private worksite index and a government worksite index. Government worksites are broken down into state, county, and city levels. Each type of worksite is given a score from 0 (no restrictions) to 4 ( $100 \%$ ban) Private worksites account for $1 / 2$ and each type of government worksite accounts for $1 / 6$ of the worksite index. The public places index has seven categories: hospitals, grocery stores, public transit, public schools, indoor sports arenas, retail stores, and bars/taverns. Each of these is scored from 0 (no restrictions) to $2(100 \%$ ban). These scores are summed to form the public places index. The restaurant index ranges from 0 (no restrictions) to 3 (100\% ban). Each separate index is based on a total of 24 and accounts for $1 / 1$ of the total clean indoor air restrictions index. $\mu=28.80, \sigma=10.56$, range $2-46$.

School smoking policy

Weighted index of smokers and non-smokers within a given school who report their school smoking policy, where $0=$ students allowed to smoke anywhere on school property, $1=$ students allowed to smoke outside the building, $2=$ students allowed to smoke in a smoking area, and $3=$ students not allowed to smoke anywhere on school property. $\mu=2.58, \sigma=$ 0.54 .

Cumulative number of tobacco

Number of grades (1-8) where tobacco use and its effects were discussed during a regular class period. $\mu=3.29, \sigma=2.16$.

classes

Minimum age purchase restrictions

Vending machine restriction

Limits on free sample distributions

Anti-tobacco media exposure

Dichotomous indicator variable $=1$ in communities where cigarette purchasers must be at least 18 years of age; otherwise $=0$. $\mu=0.81, \sigma=0.40$.

Dichotomous indicator variable $=1$ in communities where vending machines are banned; otherwise $=0 . \mu=0.05, \sigma=0.22$.

Dichotomous indicator variable $=1$ in communities where distribution of free samples of cigarettes are prohibited; otherwise $=0 . \mu=0.08, \sigma=0.27$

Index within a given school of exposure to anti-tobacco advertising through the following media: television, radio, billboards, posters or pamphlets, newspapers or magazines, community meeting or event, church or temple, hospital or doctor's office, other public places, and school. Each student was asked to report the frequency of seeing messages that discourage people from smoking in these media in the past month. The frequency categories range from 0 (never) to 4 (very often). The score for a given individual is computed as sum of scores for each media type divided by the maximum possible score. $\mu=0.50, \sigma$ $=0.05$

Pro-tobacco media exposure

Index within a given school of exposure to anti-tobacco advertising through the following media: television, radio, billboards, posters or pamphlets, newspapers or magazines, community meeting or event, church or temple, hospital or doctor's office, other public places, and school. Each student was asked to report the frequency of seeing messages that make smoking look like an attractive or fun thing to do in these media in the past month. The frequency categories range from 0 (never) to 4 (very often). The score for a given individual is computed as sum of scores for each media type divided by the maximum possible score. $\mu=0.37, \sigma=0.04$.

Male

Age (years)
13
14
15
16
Race/ethnicity
White
Black
Hispanic
Canadian
Other race/ethnicity
COMMIT intervention sit

Dichotomous indicator for males $=1$ and for females $=0 . \mu=0.49, \sigma=0.50$.

Dichotomous indicator $=1$ for those 13 years old; otherwise $=0 . \mu=0.07, \sigma=0.25$.

Dichotomous indicator $=1$ for those 14 years old; otherwise $=0 . \mu=0.65, \sigma=0.48$.

Dichotomous indicator $=1$ for those 15 years old; otherwise $=0 . \mu=0.24, \sigma=0.43$.

Reference category for age. $\mu=0.04, \sigma=0.19$.

Reference category for race/ethnicity. $\mu=0.66, \sigma=0.47$

Dichotomous indicator $=1$ for blacks; otherwise $=0 . \mu=0.11, \sigma=0.31$.

Dichotomous indicator $=1$ for Hispanics; otherwise $=0 . \mu=0.12, \sigma=0.32$.

Dichotomous indicator $=1$ for those from a Canadian site; otherwise $=0 . \mu=0.10, \sigma=0.29$.

Dichotomous indicator $=1$ for those who are not white, black, Hispanic, or Canadian; otherwise $=0 . \mu=0.10, \sigma=0.30$.

Dichotomous indicator $=1$ for those in an intervention community and 0 for those in a comparison community. $\mu=0.51, \sigma=0.50$.

Year

Dichotomous indicator $=1$ for those surveyed in 1992 and 0 for those surveyed in $1990 . \mu=0.51, \sigma=0.50$.

variation in the prices of goods and services that teenagers might be expected to buy for themselves. Items in the index included a standard hamburger, pizza, beer, pair of men's jeans, first-run movie, bottle of Coke, and a game of bowling. Prices were taken from data published by the American Chamber of Commerce Research Association (ACCRA) for the third quarters of 1990 and $1992 .^{28}{ }^{29}$ ACCRA reports list price information for many urban areas across the nation, however, not all COMMIT communities were represented. In these instances, data from an urban area from the same state with similar characteristics were substituted for data from each missing community. Because the ACCRA reports do not include Canadian communities, information on prices of the standard commodities was obtained by phone interviews with merchants in the two Canadian COMMIT communities. The average price of each commodity for a given year across all communities was set equal to 1 and relative prices calculated for each commodity in each community. The value of the teenage price index in each community is the mean of the relative prices of the seven commodities, with each commodity's price receiving equal weight in the overall index. The price of cigarettes in a given community was divided by this index to yield the adjusted price of cigarettes in that community.

Indices measuring exposure to pro-tobacco and anti-tobacco advertising were created from responses to questions about how often ninthgraders in each school in the sample saw or heard pro-tobacco and anti-tobacco messages, programmes, or advertisements on television, radio, billboards, and other means in the past month. To remove any correlation between this measure of exposure to advertising and both an individual's smoking status and the prevalence of smoking in a school, indices with values for each school were constructed as the weighted mean of responses by both smokers and non-smokers in a school where the weights were the proportion of smokers and non-smokers in the entire sample.

The stringency of a given school's smoking policy was measured in a similar fashion as the weighted mean of ninth-graders' responses to the question: "What is your school's rule or policy about cigarette smoking by students?". Responses were: allowed to smoke anywhere; allowed to smoke in smoking area; allowed to 
Table 2 Logistic estimates of smoking participation equations; policy variables entered singly

\begin{tabular}{|c|c|c|c|c|c|c|}
\hline \multirow[b]{2}{*}{ Independent variables } & \multicolumn{2}{|c|}{ Overall } & \multicolumn{2}{|c|}{ Boys } & \multicolumn{2}{|c|}{ Girls } \\
\hline & Policy variable & Cigarette price & Policy variable & Cigarette price & Policy variable & Cigarette price \\
\hline Cigarette price only & & $-0.56^{\star}(-2.87)$ & & $-0.97^{\star}(-4.27)$ & & $-0.21(-0.89)$ \\
\hline COMMrT intervention site & $-0.09(-1.39)$ & $-0.57^{\star}(-2.92)$ & $-0.13(-1.89)$ & $-0.98 \star(-4.28)$ & $-0.04(-0.53)$ & $-0.22(-0.92)$ \\
\hline Clean indoor air restrictions & $-0.00(-1.37)$ & $-0.48^{\star}(-2.29)$ & $-0.01 *(-2.37)$ & $-0.82^{\star}(-3.41)$ & $-0.00(-0.22)$ & $-0.19(-0.75)$ \\
\hline School smoking policy & $-0.13(-1.43)$ & $-0.63^{\star}(-3.01)$ & $-0.12(-1.10)$ & $-1.04 *(-4.35)$ & $-0.15(-1.48)$ & $-0.27(-1.08)$ \\
\hline Cumulative number of tobacco classes & $-0.02^{\star}(-2.16)$ & $-0.55^{\star}(-2.80)$ & $-0.02(-1.15)$ & $-0.96^{\star}(-4.22)$ & $-0.03^{\star}(-1.99)$ & $-0.20(-0.83)$ \\
\hline Minimum age purchase restriction & $-0.26^{\star}(-2.86)$ & $-0.33(-1.51)$ & $-0.30 \star(-3.14)$ & $-0.71^{\star}(-2.87)$ & $-0.23(-1.83)$ & $-0.01(-0.02)$ \\
\hline Vending machine restrictions & $-0.17(-1.17)$ & $-0.59^{\star}(-2.99)$ & $-0.14(-0.81)$ & $-0.99^{\star}(-4.34)$ & $-0.22(-1.49)$ & $-0.24(-1.01)$ \\
\hline Limits on free sample distribution & $-0.19(-1.53)$ & $-0.60 \star(-3.04)$ & $-0.10(-0.69)$ & $-0.99^{\star}(-4.35)$ & $-0.28^{\star}(-2.30)$ & $-0.26(-1.09)$ \\
\hline Anti-tobacco media exposure & $1.57^{\star}(2.09)$ & $-0.56^{\star}(-2.87)$ & $0.75(0.86)$ & $-0.97^{\star}(-4.26)$ & $2.30 \star(2.42)$ & $-0.21(-0.89)$ \\
\hline Pro-tobacco media exposure & $1.86^{\star}(1.97)$ & $-0.48^{*}(-2.41)$ & $2.93^{\star}(2.92)$ & $-0.84^{\star}(-3.72)$ & $0.80(0.65)$ & $-0.18(-0.72)$ \\
\hline Sample size & \multicolumn{2}{|c|}{15432} & \multicolumn{2}{|c|}{7833} & \multicolumn{2}{|c|}{7599} \\
\hline
\end{tabular}

*Statistically significant at $P \leqslant 0.05$.

$T$-ratios are in parentheses. Each row represents a different specification which, in addition to price and the tobacco-related policy noted in that row, includes: an intercept, indicators of gender, age, year, and race/ethnicity/natural origin. The results for these variables are available upon request.

smoke outside; and no smoking allowed, and the weights were the proportion of smokers and non-smokers in the entire sample.

Ease of access to cigarettes was measured by three indicator variables to reflect prevailing vending machine, sampling, and minimum age for purchase regulations in a community in a given year. These variables indicate either a ban on vending machines or free samples or restriction of purchase of cigarettes to those 18 or older, respectively. Information for these variables was obtained from COMMIT's legislative tracking database summarising major local tobacco control policies and a 1993 National Cancer Institute monograph on local tobacco control ordinances. ${ }^{30}$

\section{ANALYSIS}

Multivariate logistic regression models were estimated to examine the role of the price of cigarettes, other policy-related variables, COMMIT status, and demographic characteristics of ninth-graders on smoking participation among all ninth-graders and intent to smoke among non-smokers. To account for the clustered nature of the COMMIT sample, estimations were performed using SUDAAN. ${ }^{31}$ This statistical software programme accounts for complex sampling designs and computes appropriate standard errors. Standard errors obtained from SUDAAN will be inflated relative to estimated standard errors which do not reflect clustering to the extent that the responses from within a given school are correlated, hence, this approach yields conservative estimates of the statistical significance of the effects of the various independent variables on ninth-grade smoking behaviour.

Price elasticity is defined as the percentage change in a dependent variable (in the cases considered herein, smoking participation and intent to smoke) divided by the percentage change in price. Price elasticities are estimated at the mean level of the dependent and price variables in the sample. For example, a price elasticity for smoking participation of -0.4 indicates that a $10 \%$ rise in the price of cigarettes will result in a $4 \%$ reduction in the cigarette smoking participation rate. Estimates presented in this paper were calculated using logit coefficients and the formula:

$$
\eta=\beta\left(1-d^{\star}\right) p^{\star}
$$

where $\eta=$ the price elasticity, $\beta=$ the estimated logit coefficient (a measure of the difference in the value of the dependent variable associated with a unitary price difference), $\mathrm{d}^{\star}=$ the mean of the dependent variable (either participation or intention) in the sample, and $p^{\star}=$ the average price of cigarettes in the sample.

\section{Results}

Logistic estimates of the smoking participation and intent to smoke among non-smokers equations are presented in tables $2,3,4$, and 5 . Calculated price elasticities are presented in table 6. Because a number of smoking control variables are site specific, and correlated with each other and with the price of cigarettes, alternative models are presented to demonstrate how the coefficients for the price variable are affected by the inclusion of other policy

Table 3 Logistic estimates of intention to smoke among non-smokers equations; policy variables entered singly

\begin{tabular}{|c|c|c|c|c|c|c|}
\hline \multirow[b]{2}{*}{ Independent variables } & \multicolumn{2}{|c|}{ Overall } & \multicolumn{2}{|c|}{ Boys } & \multicolumn{2}{|c|}{ Girls } \\
\hline & Policy variable & Cigarette price & Policy variable & Cigarette price & Policy variable & Cigarette price \\
\hline $\begin{array}{l}\text { Cigarette price only } \\
\text { COMMrT intervention site } \\
\text { Clean indoor air restrictions } \\
\text { School smoking policy } \\
\text { Cumulative number of tobacco classes } \\
\text { Minimum age purchase restriction } \\
\text { Vending machine restrictions } \\
\text { Limits on free sample distribution } \\
\text { Anti-tobacco media exposure } \\
\text { Pro-tobacco media exposure } \\
\text { Sample size }\end{array}$ & $\begin{array}{c}0.01(0.18) \\
0.00(1.57) \\
-0.06(-0.66) \\
-0.02^{\star}(-2.06) \\
0.09(1.13) \\
-0.09(-0.59) \\
-0.15(-1.25) \\
1.75^{\star}(3.26) \\
1.10(1.41)\end{array}$ & $\begin{array}{l}-0.61^{\star}(-3.64) \\
-0.61^{\star}(-3.64) \\
-0.67^{\star}(-3.82) \\
-0.63^{\star}(-3.65) \\
-0.60^{\star}(-3.56) \\
-0.68^{\star}(-3.61) \\
-0.62^{\star}(-3.68) \\
-0.63^{\star}(-3.76) \\
-0.62^{\star}(-3.67) \\
-0.56^{\star}(-3.10) \\
46\end{array}$ & $\begin{array}{c}-0.02(-0.25) \\
0.00(0.35) \\
0.05(0.46) \\
0.00(0.15) \\
0.01(0.07) \\
-0.06(-0.26) \\
-0.12(-0.66) \\
1.46(1.71) \\
1.43(1.45)\end{array}$ & $\begin{array}{l}-0.58^{\star}(-2.37) \\
-0.58^{\star}(-2.38) \\
-0.60^{\star}(-2.25) \\
-0.55^{\star}(-2.21) \\
-0.58^{\star}(-2.37) \\
-0.58^{\star}(-2.15) \\
-0.58^{\star}(-2.41) \\
-0.60^{\star}(-2.48) \\
-0.58^{\star}(-2.37) \\
-0.51^{\star}(-1.97) \\
93\end{array}$ & $\begin{array}{c}0.03(0.40) \\
0.01(1.72) \\
-0.13(-1.20) \\
-0.05^{\star}(-2.90) \\
0.16(1.35) \\
-0.12(-0.82) \\
-0.18(-1.41) \\
2.02^{\star}(2.61) \\
0.74(0.66)\end{array}$ & $\begin{array}{l}-0.64^{\star}(-2.90) \\
-0.64^{\star}(-2.87) \\
-0.75^{\star}(-3.24) \\
-0.69^{\star}(-3.04) \\
-0.61^{\star}(-2.75) \\
-0.78^{\star}(-3.08) \\
-0.66^{\star}(-2.93) \\
-0.67^{\star}(-2.99) \\
-0.65^{\star}(-2.93) \\
-0.61^{\star}(-2.56) \\
53\end{array}$ \\
\hline
\end{tabular}

¿Statistically significant at $\mathrm{P} \leqslant 0.05$.

$T$-ratios are in parentheses. Each row represents a different specification which, in addition to price and the tobacco related policy noted in that row, includes: an intercept, indicators of gender, age, year, and race/ethnicity/natural origin. The results for these variables are available upon request. 
Table 4 Logistic estimates of snoking participation equations; all policy and independent variables entered together

\begin{tabular}{|c|c|c|c|}
\hline Indipendent variables & Overall & Boys & Girls \\
\hline Cigarette price & $-0.32(-0.94)$ & $-0.66^{\star}(-2.60)$ & $-0.04(-0.16)$ \\
\hline COMMIT intervention site & $-0.07(-1.14)$ & $-0.13(-1.86)$ & $0.03(0.30)$ \\
\hline Clean indoor air restrictions & $0.00(0.56)$ & $-0.00(-0.26)$ & $0.01(1.02)$ \\
\hline School smoking policy & $-0.15(-1.53)$ & $-0.17(-1.43)$ & $-0.14(-1.24)$ \\
\hline $\begin{array}{l}\text { Cumulative number of tobacco } \\
\text { classes }\end{array}$ & $-0.02(-1.80)$ & $-0.01(-0.94)$ & $-0.02(-1.73)$ \\
\hline Minimum age purchase restriction & $-0.33^{\star}(-2.86)$ & $-0.30^{*}(-2.27)$ & $-0.36^{\star}(-2.61)$ \\
\hline Vending machine restrictions & $0.01(0.03)$ & $-0.07(-0.22)$ & $0.08(0.31)$ \\
\hline Limits on free sample distribution & $-0.11(-0.57)$ & $0.08(0.34)$ & $-0.29(-1.32)$ \\
\hline Anti-tobacco media exposure & $2.27^{\star}(3.09)$ & $1.46(1.56)$ & $2.97^{\star}(3.17)$ \\
\hline Pro-tobacco media exposure & $1.71(1.85)$ & $2.50 *(2.32)$ & $0.93(0.81)$ \\
\hline Male & $-0.19^{\star}(-4.35)$ & & \\
\hline \multicolumn{4}{|l|}{ Age (years) } \\
\hline 13 & $-1.15^{\star}(-8.58)$ & $-1.23^{\star}(-6.89)$ & $-0.99^{\star}(-5.79)$ \\
\hline 14 & $-1.14^{\star}(-12.12)$ & $-1.28 *(-9.92)$ & $-0.94^{\star}(-6.97)$ \\
\hline 15 & $-0.64^{\star}(-6.78)$ & $-0.72 *(-5.41)$ & $-0.49^{\star}(-3.34)$ \\
\hline \multicolumn{4}{|l|}{ Race/ethnicity } \\
\hline Black & $-0.94^{\star}(-9.26)$ & $-0.89^{\star}(-5.64)$ & $-0.99^{\star}(-8.55)$ \\
\hline Hispanic & $0.00(0.03)$ & $0.04(0.36)$ & $-0.02(-0.16)$ \\
\hline Other race/ethnicity & $-0.22^{\star}(-2.61)$ & $-0.22^{\star}(-2.08)$ & $-0.22(-1.91)$ \\
\hline Canadian & $0.62^{\star}(1.97)$ & $1.20 *(3.39)$ & $0.12(0.30)$ \\
\hline 1992 & $0.17^{\star}(2.14)$ & $0.23 *(2.73)$ & $0.11(1.08)$ \\
\hline Intercept & $-0.80(-0.94)$ & $-0.09(-0.09)$ & $-1.59(-1.57)$ \\
\hline$-2 \log$ likelihood & 15219.2 & 7258.1 & 7933.1 \\
\hline Sample size & 15432 & 7833 & 7599 \\
\hline
\end{tabular}

* Statistically significant at $P \leqslant 0.05$.

$T$-ratios are in parentheses.

Table 5 Logistic estimates of intention to smoke among non-smokers equations; all policy and independent variables entered together

\begin{tabular}{llll}
\hline Independent variables & Overall & Boys & Girls \\
\hline Cigarette price & $-0.69^{\star}(-3.44)$ & $-0.53(-1.93)$ & $-0.81^{\star}(-3.01)$ \\
COMMIT intervention site & $0.02(0.41)$ & $-0.01(-0.10)$ & $0.06(0.66)$ \\
Clean indoor air restrictions & $0.00(1.26)$ & $0.01(0.86)$ & $0.00(0.82)$ \\
School smoking policy & $-0.00(-0.04)$ & $0.09(0.78)$ & $-0.07(-0.54)$ \\
Cumulative number of tobacco & $-0.02(-1.91)$ & $0.00(0.30)$ & $-0.05^{\star}(-2.89)$ \\
$\quad$ classes & & & \\
Minimum age purchase restriction & $0.04(0.44)$ & $-0.03(-0.27)$ & $0.11(0.74)$ \\
Vending machine restrictions & $0.24(0.99)$ & $0.28(0.63)$ & $0.21(0.91)$ \\
Limits on free sample distribution & $-0.42^{\star}(-2.27)$ & $-0.41(-1.11)$ & $-0.44^{\star}(-2.37)$ \\
Anti-tobacco media exposure & $1.73^{\star}(2.98)$ & $1.52(1.53)$ & $1.95^{\star}(2.61)$ \\
Pro-tobacco media exposure & $1.56^{\star}(2.01)$ & $1.87(1.86)$ & $1.19(1.06)$ \\
Male & $-0.16^{\star}(-2.79)$ & & \\
Age (years) & & & \\
13 & $0.55^{\star}(2.87)$ & $0.53^{\star}(2.13)$ & $0.63^{\star}(2.08)$ \\
14 & $0.46^{\star}(2.74)$ & $0.31(1.36)$ & $0.66^{\star}(2.47)$ \\
15 & $0.32(1.88)$ & $0.25(1.12)$ & $0.43(1.54)$ \\
Race/ethnicity & & & \\
Black & $-0.22^{\star}(-2.57)$ & $-0.19(-1.51)$ & $-0.25^{\star}(-2.10)$ \\
Hispanic & $0.15(1.73)$ & $0.16(1.33)$ & $0.14(1.18)$ \\
Other race/ethnicity & $0.02(0.22)$ & $0.11(0.82)$ & $-0.05(-0.38)$ \\
Canadian & $1.02^{\star}(3.34)$ & $1.00^{\star}(2.37)$ & $1.04^{\star}(2.63)$ \\
1992 & $0.28^{\star}(4.18)$ & $0.30^{\star}(2.92)$ & $0.27^{\star}(2.81)$ \\
Intercept & $-2.23^{\star}(-3.48)$ & $-2.87^{\star}(-3.18)$ & $-1.94^{\star}(-2.17)$ \\
-2 log likelihood & 11402.1 & 5461.0 & 5924.9 \\
Sample size & 11846 & 5893 & 5953 \\
\hline
\end{tabular}

ॠ Statistically significant at $P \leqslant 0.05$.

$T$-ratios are in parentheses.

Table 6 Estimated price elasticities of smoking behaviour in young people

\begin{tabular}{|c|c|c|c|}
\hline & Overall & Boys & Girls \\
\hline $\begin{array}{l}\text { Panel A: smoking participation } \\
\text { Price only model } \\
\text { Full model }\end{array}$ & $\begin{array}{l}-0.87^{\star} \\
-0.49\end{array}$ & $\begin{array}{l}-1.51^{\star} \\
-1.02^{\star}\end{array}$ & $\begin{array}{l}-0.32 \\
-0.06\end{array}$ \\
\hline $\begin{array}{l}\text { Panel B: intention to smoke } \\
\text { Price only model } \\
\text { Full model }\end{array}$ & $\begin{array}{l}-0.95^{\star} \\
-1.07^{\star}\end{array}$ & $\begin{array}{l}-0.92^{\star} \\
-0.84\end{array}$ & $\begin{array}{l}-0.99^{\star} \\
-1.26^{\star}\end{array}$ \\
\hline
\end{tabular}

* Estimates derived from statistically significant logit coefficients.

The price elasticities are based on estimates of models presented in tables 2-5.

variables. First, tables 2 and 3 contain estimates of coefficients of the price and policy variables obtained from smoking participation and intent equations which contain all demographic variables, the year, the real price of cigarettes, and at most one measure related to tobacco control policy. This strategy minimises the multi-colinearity that might result from including many highly correlated policy measures in these models. Deliberately omitting other policy variables may, however, bias these estimates of the effects of the included variables on smoking behaviour in the young. The model specifications presented in tables 4 and 5 address this bias issue by including all policy-related variables in the smoking participation and intent to smoke equations. The multi-colinearity that may result from including the large set of policy-related variables in the models in these tables may, however, make it difficult to estimate the true impact of these policies on smoking behaviour in young people. ${ }^{13}$

\section{POLICY-RELATED VARIABLES}

The price of cigarettes is found to have a negative and statistically significant impact on smoking participation in all specifications for boys, but not for girls. The magnitude and statistical significance of the price coefficients for the combined sample (boys and girls) in the smoking participation equations are reduced somewhat by the inclusion of the other policy variables and seem to be particularly affected by the correlation between price and minimum age purchase restrictions in the sample (tables 2 and 4 ). Estimates of the price elasticity of participation, as reported in table 6 , range from -1.51 to -1.02 for boys and from -0.32 to -0.06 for girls. For the combined sample, the range is -0.87 to -0.49 .

The effect of price on the intent to smoke within a year among non-smokers is negative, generally consistent, and statistically significant across gender groups. Estimated price elasticities of intent to smoke (table 6) range between -0.92 to -0.84 for boys and -1.26 to -0.99 for girls and -1.07 to -0.95 overall. The results for both indicators of smoking behaviour in the young suggest that increases in the price of cigarettes would reduce smoking participation rates among ninth-graders and could have a more lasting impact on smoking rates in the general population (both male and female) if the reductions in the intent to smoke among ninth-graders associated with increased cigarette prices result, as the adolescents grow older, in reductions in smoking participation.

Policies restricting smoking in various public places and particularly schools seem to have little or no effect on the smoking behaviour of ninth-graders in our sample. The coefficients on the indicators for restrictions on smoking in public places and for school smoking policies are not statistically significant in most of the models. Only in the limited specification for boys (table 2 ) is the coefficient on restrictions in public places, negative and significant, but even in that equation, the coefficient's value is small.

In contrast to the insignificant effects of policies restricting smoking in schools and other public places on the smoking behaviour of ninth-graders, laws and ordinances that restrict purchase of cigarettes to those 18 years of age and older, do appear to have a negative effect on smoking participation by both boys and girls, although these restrictions do not 
effect ninth-graders' reported intention to smoke (tables 2-5). Moreover, the estimated effect of these age restrictions is substantial. Based on the estimated coefficients presented in tables 2 and 4 imposition of a minimum cigarette purchase age restriction of 18 years is associated with a decrease of 0.04 to 0.05 in the probability of smoking among ninthgraders. Age-based restrictions on cigarette purchase that apply to ninth-graders, however, will have less effect on them as they age and therefore less effect on their intent and ability to smoke in the future, as seen in the estimated coefficients reported in the intent equations in table 3 and table 5 . Bans on vending machines are not associated with a reduction in either smoking participation or intent to smoke among the young people in our sample. Restrictions on the distribution of free, sample cigarettes were associated with a small estimated reduction in smoking participation and the intent to smoke, particularly among girls. Both of these findings need to be treated with caution, however, because each of these policies were in effect in very few of the 21 communities in our sample.

Lastly, among the policy-relevant variables included in the equations, the estimated coefficient of the media exposure variables (tables $2-5$ ) give only very modest support to the notion that media-focused policy interventions will be effective in reducing smoking among ninth-graders. Coefficients on the anti-tobacco media variable are positive and significant in the overall participation and intent equations and in the equations for girls: suggesting, somewhat paradoxically, that an increase in exposure to anti-tobacco media activity may be associated with increases in both participation and in intent among some ninth-graders. These results are contradicted somewhat by the finding that the cumulative number of tobacco education classes in schools, activities which convey anti-tobacco messages, are associated with small reductions in smoking and in the intent to smoke in the same population groups. The coefficients on the pro-tobacco media exposure measure, although positive, as expected, only achieve statistical significance at traditionally accepted levels $(P \leqslant 0.05)$ in some of the equations presented for males and all ninth-graders. This finding gives only limited support to the frequently discussed notion that high levels of exposure to cigarette advertising, targeted at young people or otherwise, lead to an increase in cigarette smoking among ninthgraders.

OTHER FINDINGS

Boys are found to be less likely to smoke and to intend to smoke than girls, after controlling for other determinants of smoking behaviour. Blacks and other non-whites/non-Hispanics are less likely to smoke than whites. After controlling for other determinants of smoking, Canadian boys are more likely to smoke and young Canadians of both genders expect to smoke in the future at a higher rate than young residents of the United States. Few statistically significant differences were identified between Hispanic and white ninth-graders.

Older youths were more likely to smoke than younger ones. However, younger non-smokers were more likely to report that they intend to smoke in the future than older non-smokers. One explanation for these contrary patterns by age is that some proportion of younger non-smokers who intend to smoke will in fact become smokers as they age.

The prevalence of smoking by ninth-graders, as well as their intent to smoke in the future, is higher in 1992 than 1990. This finding suggests that other factors, not reflected in our analysis, were having a significant effect on cigarette smoking behaviour in young people in recent years.

\section{Discussion}

The results of our analysis indicate that a variety of tobacco control policies, including higher excise taxes, which lead to increases in retail cigarette prices, can be effective in reducing smoking participation among ninthgraders and probably among a wider age spectrum of young people, as suggested by the impact of price on the intent to smoke. The estimated price elasticities are generally of the same order of magnitude as reported in earlier work on cigarette demand among teens by Lewit and his colleagues ${ }^{78}$ and more recent work by Chaloupka and Grossman. ${ }^{13} \mathrm{We}$ also find, as reported by Lewit and Coate, that the price elasticity of participation is substantially higher for males than for females. ${ }^{32}$ The additional finding, reported here for the first time, that high prices are associated with large reductions in the intent to smoke among young non-smokers, suggests that some portion of price/tax-induced reductions in smoking participation among ninth-graders may be sustained into adulthood and thus lead to substantial long-run improvements in health.

We do not find, however, that stronger restrictions on smoking in public places or in schools are associated with significant reductions in the prevalence of smoking among ninth-graders. This result is somewhat inconsistent with the research of Wasserman et $a l^{9}$ and Chaloupka and Grossman ${ }^{13}$ who find that smoking restrictions do lead to reductions in smoking by young people.

The finding that restricting the legal purchase of cigarettes to those at least 18 years old correlates with reduced smoking participation among ninth-graders suggests that recently implemented efforts which resulted in a national minimum purchase age of 18 , and other efforts at the national, state, and local levels, resulting from the Synar amendments, the FDA's final rule on tobacco and children and other independent initiatives, to more effectively limit access to tobacco by young people, will likely be effective in at least deterring cigarette use. The long range impact of these access measures on smoking by older teenagers and young adults and ultimately on the health of the population, however, is unknown at this time. Unlike higher prices, which are found to have a negative effect on 
both smoking participation and intention, restrictions on access, even if they are effective in reducing smoking initiation in young smokers, do not appear associated with reduced expectations of future smoking among non-smokers. These differences in the longer-run effects of a price increase and of restrictions on access may be a function of the age-limited nature of the access restrictions themselves. Restrictions on access will typically be without force after age 17, but higher prices pose a deterrent to smokers of all ages.

Key elements of the recently established comprehensive national programme to reduce tobacco use by children and adolescents include FDA regulations to reduce the appeal of tobacco to children by restricting certain types of advertising and promotional activities that are thought to appeal particularly to children and an FDA proposal to require tobacco companies to educate young people via the public media about the health dangers associated with tobacco use. Our analyses provide only limited support for the likely effectiveness of either policy. Although we do find a positive correlation between measures of smoking behaviour and self-reported frequency of exposure to pro-tobacco media, the relationships are not consistently statistically significant across different gender groups and model specifications. Moreover, our finding of a positive, statistically significant relationship between smoking participation and intent to smoke and self-reported exposure to anti-tobacco media do not support the notion that a national, multi-media campaign about the dangers of tobacco will substantially reduce smoking among young people. However, further research on the effects of pro-tobacco and anti-tobacco advertising on young smokers are warranted before firm conclusions may be drawn about the potential effectiveness of media-focused policies. A somewhat encouraging result for tobacco control policymakers is the finding that tobacco education classes in the schools appear to reduce by a small amount smoking-related behaviours among ninthgraders, particularly girls. This finding suggests that increased emphasis on anti-tobacco education in the schools should be a component of any national programme to reduce tobacco use by children. Support for this research has been provided by the National Cancer Institute and the Robert Wood Johnson Foundation. We
are indebted to our colleagues at the 11 COMMIT research are indebted to our colleagues at the 11 COMMIT research
sites, the COMMIT coordinating center, Information Managesites, the COMMIT coordinating center, Information Management Services, Inc., and staff at the National Cancer Institute who planned and coordinated
activities of the COMMIT study.

1 US Department of Health and Human Services. Reducing the health consequences of smoking: 25 years of progress. $A$ report of the Surgeon General, 1989. Rockville, Maryland: Public Health Service, Centers for Disease Control, Office on Smoking and Health, 1989. (DHHS Publication No (CDC) 89-8411.)

2 US Centers for Disease Control. Tobacco use and usual source of cigarettes among high school students-United States, 1995. MMWR 1996;45:413-18.

3 US Department of Health and Human Services. Regulations restricting the sale and distribution of cigarettes and smokeless tobacco to protect children and adolescents; final rule. Docket number $95 \mathrm{~N}-0253$, August 1996
4 Institute of Medicine. Growing up tobacco free: preventing nicotine addiction in children and youths. Washington DC: National Academy Press, 1994.

5 US Department of Health and Human Services. Preventing tobacco use among young people. A report of the Surgeon General, 1994. Atlanta, Georgia: Public Health Service, Centers for Disease Control and Prevention, Office on Smoking and Heaith, 1994 (US Government Printing Office No S/N 017-001-00491-0.)

6 National Cancer Institute. The impact of cigarette excise taxes on smoking among children and adults: summary report of a National Cancer Instilute Expert Panel. Bethesda, Maryland: and Control, Cancer Control Science Program, 1993.

7 Lewit EM, Coate D, Grossman M. The effects of government regulations on teenage smoking. $f$ Law Econ government regulat

8 Grossman M, Coate D, Lewit EM, Shakotko RA. Economic and other factors in youth smoking, final report. Cambridge, Massachusetts: National Bureau of Economic Research, 1983.

9 Wasserman J, Manning WG, Newhouse JP, Winkler JD. The effects of excise taxes and regulations on cigarette smoking. 7 Health Econ 1991;10:43-64.

10 Chaloupka FJ. Clean indoor air laws, addiction, and cigarette smoking, Appl Econ 1992;24:193-205.

11 Chaloupka FJ, Saffer $\mathrm{H}$. Clean indoor air laws and the demand for cigarettes. Contemporary Policy Issues 1992, 10:72-83.

12 Chaloupka FJ, Wechsler H. Price, tobacco control policies, and smoking among young adults. Working Paper No 5012. smoking among young adults. Working Paper No 5012. Research, February 1995.

13 Chaloupka FJ, Grossman M. Price, tobacco control policies and youth smoking. Working Paper No 5470. Cambridge, Massachusetts: National Bureau of Economic Research, December 1996.

14 DiFranza JR, Norwood BD, Garner DW, Tye JB. Legislative efforts to protect children from tobacco. $\mathcal{F} A M A$ 1987; 257:2287-9.

15 Jason LA, Ji PY, Anes $M D$, Birkhead SH, Active enforcement of cigarette control laws in the prevention of cigarette sales to minors. $\mathcal{F} A M A$ 1991;266:3159-61.

16 Weinbaum Z, Quinn V, Roeseler A, et al. Estimates of retailers willing to sell tobacco to minors-California, AugustSeptember 1995 and June-July 1996. MMWR 1996
50:1095-9.

17 Altman DG, Rasenick-Douss L, Foster V, Tye JB. Sustained efforts of an educational program to reduce sales of cigartes to minors. Am $\mathcal{F}$ Public Health 1991;81:891-3.

18 COMMIT Research Group. Community Intervention Trial for Smoking Cessation: summary of design and intervention. $\mathcal{F}$ Natl Cancer Inst 1991;83:1620-8.

19 Mattson ME, Cummings KM, Lynn WR, et al. Evaluation plan for the community intervention trial for smoking cessation (COMMIT). Int $Q$ Commun Health Educ 1991; 11:271-90.

20 COMMIT Research Group. Community Intervention Trial for Smoking Cessation (COMMIT): I. Cohort results from a four-year community intervention. Am $\mathcal{f}$ Public Health 1995;85:183-92.

21 COMMIT Research Group. Community Intervention Trial for Smoking Cessation (COMMIT): II. Changes in adult for Smoking Cessation (COMMIT): Il. Changes in adult 85:193-200.

22 Anon. The tax burden on tobacco. $A$ historical compilation. Washington, DC: Tobacco Institute, 1991; vol. 26. Table 13-B and table 15.

23 Anon. The tax burden on tobacco. $A$ historical compilation. Washington, DC: Tobacco Institute, 1993; vol. 28. Table 13-B and table 15 .

24 US Bureau of the Census. Statistical abstract on the United States. Table 756. Washington, DC: Bureau of the Census, 1993.

25 Non-Smokers' Rights Association, (Canada), 130 Albert Street, Suite 103, Ottawa, Ontario, Canada. (Personal communication.)

26 Statistics Canada. The Consumer Price Index for Canada. Ontario: Statistics Canada, 1990, 1992.

27 Foreign exchange rates, Hio. Board of Governors of the Federal Reserve System Statistical Release.

28 American Chamber of Commerce Research Association. Cost of living index: comparative data for 308 urban areas, third quarter 1990. Louisville, Kentucky: American Chamber of Commerce Research Association.

29 American Chamber of Commerce Research Association. Cost of living index: comparative data for 300 urban areas, third quarter 1992. Louisville, Kentucky: American Chamber of Commerce Research Association.

30 US Department of Health and Human Services. Major local tobacco control ordinances in the United States. Smoking and
Tobacco Control Monograph No 3. Bethesda, Maryland: Public Health Service, National Institutes of Health, 1993. (NIH Publication No 93-3532.)

31 Shah BV, Barnell BG, Hunt PN, LaVange LM. Sudaan user's manual: professional software for survey data analysis for manual: professional software for survey data analysis for
multi-stage sample designs, release 6.0 . Research Triangle multi-stage sample designs, release 6.0. Research Triangle

32 Lewit EM, Coate D. The potential for using excise taxes to reduce smoking. $₹$ Health Econ 1982;1:121-45. 